OPEN ACCESS

Edited by:

Toshiyo Tamura,

Waseda University, Japan

Reviewed by:

Shekh Md Mahmudul Islam,

University of Dhaka, Bangladesh

Vinaytosh Mishra,

Fore School of Management, India

${ }^{*}$ Correspondence:

Hassane Alami

hassane.alami@umontreal.ca

Specialty section:

This article was submitted to

Connected Health,

a section of the journal

Frontiers in Digital Health

Received: 07 June 2021 Accepted: 06 September 2021

Published: 05 October 2021

Citation:

Alami H, Lehoux P, Attieh R, Fortin J-P,

Fleet $R$, Niang $M$, Offredo $K$,

Rouquet R, Ag Ahmed MA and Ly BA (2021) A "Not So Quiet" Revolution:

Systemic Benefits and Challenges of

Telehealth in the Context of COVID-19 in Quebec (Canada).

Front. Digit. Health 3:721898 doi: 10.3389/fdgth.2021.721898

\section{A "Not So Quiet" Revolution: Systemic Benefits and Challenges of Telehealth in the Context of COVID-19 in Quebec (Canada)}

\author{
Hassane Alami 1,2*, Pascale Lehoux ${ }^{1,2}$, Randa Attieh ${ }^{3}$, Jean-Paul Fortin ${ }^{4,5}$, \\ Richard Fleet ${ }^{5,6,7}$, Marietou Niang ${ }^{8}$, Kevin Offredo ${ }^{9,10}$, Ronan Rouquet ${ }^{11}$, \\ Mohamed Ali Ag Ahmed ${ }^{12,13}$ and Birama Apho Ly ${ }^{14}$
}

${ }^{1}$ Center for Public Health Research of the University of Montreal, Montreal, QC, Canada, ${ }^{2}$ Department of Health Management, Evaluation and Policy, University of Montreal, Montreal, QC, Canada, ${ }^{3}$ Research Centre of the University of Montreal Hospital Centre, University of Montreal, Montreal, QC, Canada, ${ }^{4}$ Department of Social and Preventive Medicine, Faculty of Medicine, Laval University, Quebec, QC, Canada, ${ }^{5}$ VITAM Research Centre on Sustainable Health, Laval University, Quebec, QC, Canada, ${ }^{6}$ Department of Family Medicine and Emergency Medicine, Faculty of Medicine, Laval University, Quebec, QC, Canada, ${ }^{7}$ Research Chair in Emergency Medicine Laval University-Affiliated University Hospital Centre Hôtel-Dieu de Lévis, Levis, QC, Canada, ${ }^{8}$ Faculty of Nursing Science, Laval University, Quebec, QC, Canada, ${ }^{9}$ Faculty of Dental Medicine, Rennes 1 University, Rennes, France, ${ }^{10}$ French Society of Digital Health, Paris, France, ${ }^{11}$ Hauts-de-France Regional Health Agency (ARS), Amiens, France, ${ }^{12}$ Research Chair on Chronic Diseases in Primary Care, Sherbrooke University, Chicoutimi, QC, Canada, ${ }^{13}$ Department of Public Health, Institute of Tropical Medicine, Antwerp, Belgium, ${ }^{14}$ Faculty of Pharmacy, University of Sciences, Techniques and Technologies of Bamako, Bamako, Mali

The COVID-19 pandemic has had a major impact on health and social service systems (HSSS) worldwide. It has put tremendous pressure on these systems, threatening access, continuity, and the quality of patient care and services. In Quebec (Canada), the delivery of care and services has radically changed in a short period of time. During the pandemic, telehealth has been widely deployed and used, notwithstanding the decades-long challenges of integrating this service modality into the Quebec HSSS. Adopting a narrative-integrative approach, this article describes and discusses Quebec's experience with the deployment and utilization of telehealth in the context of COVID-19. Firstly, we introduced the achievements and benefits made with the use of telehealth. Secondly, we discussed the challenges and concerns that were revealed or accentuated by the sanitary crisis, such as: (1) training and information; (2) professional and organizational issues; (3) quality of services and patient satisfaction; (4) cost, remuneration, and funding; (5) technology and infrastructure; (6) the emergence of private telehealth platforms in a public HSSS; (7) digital divide and equity; and (8) legal and regulatory issues. Finally, the article presents recommendations to guide future research, policies and actions for a successful integration of telehealth in the Quebec HSSS as well as in jurisdictions and countries facing comparable challenges.

Keywords: COVID-19, Quebec (Canada), telehealth, sustainability, quality of care, remuneration, direct-toconsumer, digital divide 


\section{INTRODUCTION}

The COVID-19 pandemic was a "stress test" for health and social service systems (HSSS) around the world (1-3). Digital technologies were quickly identified as a lever for meeting and monitoring the care and services needs of patients and the population. Numerous telehealth initiatives and solutions have been developed and deployed in a short time. Telehealth is defined as "health care and services, as well as social, preventive, and curative services, delivered remotely by means of a telecommunication, including audiovisual exchanges for information, education and research, and treatment of clinical and administrative data purposes" $(4,5)$. Telehealth has already demonstrated its potential in the provision of routine care and services as well as in crisis (e.g., natural disasters, health emergencies) $(3,6,7)$.

This article aims to discuss the deployment and use of telehealth in Quebec (Canada) as an emergency response strategy to the COVID-19 pandemic. The thoughts in this paper derive from the literature and our collective expertise as researchers, practitioners, and/or experts in digital health, medicine and public health, health technology assessment, and health services and policy. It adopts a narrative-integrative and critical perspective with the main "objective of stimulating and encouraging debate" on telehealth in the context of COVID-19 and beyond (8). The article describes several issues that have persisted for years and that had, or could have had, an impact on the successful deployment and use of telehealth in the context of COVID-19. It also offers several recommendations and avenues to guide future policies and actions for the successful integration of telehealth in Quebec as well as in jurisdictions and countries facing comparable challenges. It also provides a basis for future in-depth empirical research on, and evaluations of the impacts of the use of telehealth in HSSS and conditions for success and sustainability.

\section{OVERVIEW OF THE HEALTH AND SOCIAL SERVICES SYSTEM OF QUEBEC (CANADA)}

To facilitate understanding of what is reported in this paper, it is important to provide some information, especially for readers who are not familiar with the Canadian and Quebec contexts. Canada is a federal state, made of 10 provinces and three territories. The provinces have significant political powers. Health and social policies fall under provincial jurisdictions (9). However, the federal government contributes to the funding of health policies, provided that the provinces comply with the Canada Health Act $(9,10)$. The Quebec HSSS, like Canada, is principally a Beveridge model. The Quebec Ministry of Health and Social Services (MSSS) is responsible for defining, coordinating and regulating the main strategic objectives, directions and priorities, and allocating resources (9). Professional federations, particularly medical ones (e.g., Federation of medical specialists of Québec -FMSQ-, Federation of general practitioners -FMOQ-), play an important role in defending the interests of their members as well as in the regulation and governance of the Quebec HSSS. On their side, professional colleges play an important role in supervising the quality of clinical practice (e.g., Quebec college of physicians CMQ-). Physicians are paid mainly on a fee-for-service basis through the public insurance system, if they do not practice in the private sector. A minority (about $2 \%$ ) practice in the private sector and are paid directly by patients and/or private insurance $(9,11)$. The other health professionals (e.g., nurses, respiratory therapists) are mostly salaried by their organizations.

\section{THE PANDEMIC AS A CATALYST FOR A "NOT SO QUIET" REVOLUTION IN QUEBEC}

In the 1960s, Quebec experienced what is known the "quiet revolution," a profound sociocultural and political innovative transformation that helped to redesign the structure of the provincial state so that it reflected the aspirations of its population (12). At the start of 2020, the COVID-19 pandemic challenged the status quo in Quebec's HSSS, particularly in the organization and delivery of services. It has served as an accelerator for wider use of telehealth, although the province has experienced significant delays in integrating care and service delivery for decades (13-15). We could speak of another "revolution," but less silent.

In addition to the specific needs of the COVID-19 context, telehealth is particularly essential given the significant shortage and the uneven distribution of health care providers over the vast territory of Quebec $\left(1,667,712 \mathrm{~km}^{2}\right)$ (13). As in other countries around the world, telehealth has made it possible to limit the transmission and spread of the virus. Clinicians in quarantine or lockdown were able to continue providing services remotely, freeing up other clinicians to provide in-person care $(1,2,16-18)$. Care and services outages were avoided, especially for patients who risked missing their in-person appointments for fear of COVID-19 (e.g., chronic pathologies, pregnancy followup, postoperative follow-up, vulnerable, and isolated patients). Telehealth has also sparked interest in training and sharing of expertise among health care providers, especially those without expertise in infectious diseases or critical care (17). In sum, telehealth has helped to optimize human resources (e.g., avoiding travel), hospital resources (e.g., avoiding overcrowding in some organizations, long queues in patient rooms), and supplies (e.g., avoiding shortages of personal protective equipment) $(2,3,19)$.

As a result, in July 2020, the number of teleconsultations in Quebec exceeded 2.2 million (1,506,083 in family medicine and 726,014 in specialty medicine) (20). According to the FMSQ, at the end of May 2020, more than $80 \%$ of specialist physicians were performing remote consultations (internal data). Telehealth represented about $70 \%$ of the activity of some physicians who had never used it before (21). Over this period, more than 15,000 physicians performed at least one remote consultation (20). These figures are unprecedented in the history of Quebec.

Quebec had not established systems and procedures for virtual care. At the onset of the pandemic, many regulatory and 
financial barriers had been lifted to facilitate the deployment of telehealth, including physicians could now be reimbursed for telehealth interventions, psychostimulants and opioids could be prescribed remotely, patients' records could be accessed outside the hospital and prescriptions digitally signed, physicians and patients no longer needed to be in a healthcare facility to perform a virtual consultation, physicians could now see patients who they had never seen physically before, and the constraints inherent in certain professional jurisdictions were alleviated (e.g., reserved acts). In addition, billing codes have been adapted to allow physicians to continue providing routine health services alongside COVID-19 services. Telephone consultations are now reimbursed even if they are excluded from the definition of telehealth in the 2005 Act on health services and social services (LSSSS) $(4,5)$. Procurement processes have been adapted and revised to accelerate the deployment of telehealth technologies in health organizations (22). The expenses inherent in the use of the technology were also largely covered by the MSSS $(23,24)$. Furthermore, Health Canada (the Canadian federal ministry of health) has accelerated the process of conformity assessment of technologies submitted by industry and their approval (22).

However, in a context where Quebec did not have a functional and integrated telehealth network throughout its territory, this rapid deployment revealed and/or accentuated several issues of a different nature and at different levels. This paper addresses more specifically: (1) training and information; (2) professional and organizational issues; (3) quality of services and patient satisfaction; (4) cost, remuneration, and funding; (5) technology and infrastructure; (6) the emergence of private telehealth platforms in a public HSSS; (7) digital divide and equity; and (8) legal and regulatory issues.

\section{Training and Information Issues}

At the outset of the pandemic, the reluctance of some clinicians and organizations to use telehealth is not simply a form of "resistance to change." There is a lack of training and information on alternative ways of providing care and services, other than inperson contact. As one clinician reported in a newspaper: "It's still weird for a physician not to be able to physically examine someone. In addition, being on Zoom $8 h$ a day is tiring" (own translation) (25). Telehealth requires skills development: remote reproduction of the face-to-face act, different body language, lack of smell for certain exams, mastery of certain technical elements, etc. $(13,15,25)$. Information is also required to perform it, including: what procedures can be performed remotely? What types of patients can be treated remotely? How and when to document patient consent and consultation (e.g., the content of justification notes and reports)? Are there specific patient rights for this type of care? Are professional responsibilities the same? Are physicians allowed to use other technologies (e.g., Facetime, Skype, and WhatsApp), especially in exceptional situations? What are the billing and remuneration conditions for telehealth activities? etc.

At the end of March 2020, the CMQ published guidelines to provide information and clarify certain questions $(26,27)$. It specified that the same ethical standards are required in telehealth (e.g., quality of the therapeutic relationship, respect for professional secrecy, obligation to follow-up or keep records). For reasons of confidentiality, physicians should never use public communication tools and social networks (e.g., Facebook, Skype, Snapchat or Twitter) to provide care and services to a patient. Given the challenges posed by the health situation, the CMQ has relaxed the requirements for written patient consent, accepting verbal consent at the start of the consultation and a note in the medical file. However, the CMQ recalled that it is up to the physician to determine whether the patient's state of health is compatible or not with a teleconsultation. This last point could pose a challenge to clinicians who have never, or rarely, used telehealth in their practice. In this regard, the literature has reported that physicians find it difficult to make clinical decisions when technology is the default solution, especially due to the difficulty in assessing the risk of missing important information and/or signs during the virtual examination (28).

Training and information may also be needed to raise awareness and familiarize patients and communities with telehealth (29). In this regard, Triana et al. (30) reported that digital literacy was a major barrier to the use of telehealth during the COVID-19 in the USA. In Quebec, the issue of training, information and involvement of patients and communities in telehealth is still very little studied and explored $(31,32)$.

\section{Professional and Organizational Issues}

Virtual consultations are more complex in a crisis context where clinical practice protocols are not available or not adapted to the situation $(33,34)$. For example, telehealth may require changes and revisions to clinical and organizational processes and practices, particularly to reflect the new roles and dynamics of clinical staff (e.g., physicians, pharmacists, and nurses), administrative and technical teams, and patients $(34,35)$. Likewise, organizations face a lack of dedicated and trained staff (e.g., nurses, administrative assistants) to receive and manage large volumes of consultation requests (e.g., confirm patient identity and contact information), perform assessments, triage and recall, and track patients.

Telehealth inevitably involves time-consuming tasks (e.g., quality testing of technology and ancillary services) $(35,36)$. Clinicians are likely to spend their time doing a lot of computer science and a little medicine. They typically respond to technical problems by abandoning technology, especially when it is not suited to their clinical practice but rather "tech-driven" and/or when it causes frustration and stress $(15,37)$. Moreover, the quality of the consultation depends on the time and workload required for its organization. In some situations, a virtual consultation is more complex and may take longer than a faceto-face session. This could have an impact on the organization of services (e.g., consultation planning, number of people consulted, follow-up before and after consultation), the work of clinical-administrative teams (e.g., workload, additional human resources), and the performance and productivity of physicians paid primarily by activity. For example, a teleconsultation could require the mobilization of at least two health professionals (e.g., physician and nurse) at the same time, especially when the patient needs to be accompanied (e.g., by a nurse), which may not be an efficient delivery process. In addition, telehealth requires 
the deployment of qualified technical personnel to ensure the proper functioning of equipment and the network: configuration, resolution of bugs, camera settings, audio, and good security practices. This staff is essential to the success of each consultation (33). In Quebec, it is very difficult to recruit and retain such expertise in public health facilities, in part because wages and working conditions are more advantageous in the private sector.

Given the urgency of the pandemic situation, a "one-sizefits-all" approach to the implementation of technologies in health departments and organizations is widely adopted. Such an approach could have weakened pre-existing and well-functioning professional and organizational collaborative networks. There can be great variability in the way services are provided and workflows organized between organizations (e.g., primary care clinic, rural hospital, and urban hospital), medical specialties, and patients' profiles (e.g., chronic pathologies, infectious diseases, and acute conditions).

\section{Quality of Services and Patient Satisfaction Issues}

Telehealth was new to many clinicians and organizations in Quebec. The quality of the remote consultation depends on the knowledge of the technology, the availability, and quality of support teams (e.g., clinical, technical, and administrative), the profile of the patient as well as the technology and the infrastructure. Suboptimal management can compromise the quality and experience of patient care and services as well as the quality of work and satisfaction of clinicians (38). The literature already documented the problems of clinician burnout caused by a technology poorly adapted to clinical realities and its negative impact on the quality of care and patient management $(38,39)$. This burden may be exacerbated in the context of COVID19 , especially given the increased personal family and childcare responsibilities of many clinicians (40).

Telehealth should, in principle, be integrated into existing clinical governance processes, although it is not included in current practice accreditation standards (e.g., validation of the capacity of good clinical practice) (41). In a pandemic context, its use could lead to collateral damage, including sub-optimal quality of service and/or missed diagnoses (e.g., incomplete or inaccurate examination) $(42,43)$. In this regard, the fact that teleconsultation constituted more than $50 \%$ of consultations during the crisis provoked a reaction from the president of the CMQ: "I was startled when I heard that it was used in almost $50 \%$ of consultations, many over the phone (...) in my opinion, there are more than 50\% of situations in which a physician has to meet [in-person] with his patient" (own translation) (44). In addition, the CMQ reported that patients with severe shortness of breath and cough, consulted via telehealth, were diagnosed with asthma without being referred for a COVID-19 test (44). It thus recognized that there were "certainly more diagnostic errors than before by simply using this technology" (own translation) (44).

According to a survey by the Canadian Medical Association, about $91 \%$ of Canadians were satisfied with their teleconsultation experience during the pandemic $(45,46)$. However, this rate should be put into perspective. In fact, evaluating the quality of services remains difficult in the context of traditional consultation, and even more so with telehealth (47). Given the exceptional nature of the situation (e.g., temporary closure of certain services, inability to travel for in-person visits), patients may accept things they would have refused in a normal situation $(25,48)$. Satisfaction might have been different if in-person visits and telehealth had been available (48). In the context of COVID-19, it was observed that emergency rooms of Quebec hospitals, some of which are more than $130 \%$ saturated, received a large number of patients referred almost automatically by their physicians for a physical examination after a virtual consultation (49). According to the "Quebec Emergency Chiefs' Grouping": "We observe a significant number of users referred to the emergency departments without having been examined by their physician [working only in teleconsultation]. (...) Users with mild or non-urgent conditions that could have been adequately treated by a face-to-face assessment are referred to the emergency departments" (own translation) (50). These patients can wait up to $12 \mathrm{~h}$ without seeing a doctor, due to overcapacity in emergency departments (50). This situation leads to double consultation for the same patient, which increases the workload for clinicians and has a negative impact on the quality and experience of care for individuals. On this point, few studies have evaluated the downstream impact of telehealth on the overall use of services and patient health outcomes [52].

Now reimbursed, the phone was widely used for remote consultations. This solution, under normal circumstances, could be considered less optimal for certain clinical scenarios (51). It can be associated with more errors, poor communication, and more incomplete examinations $(48,52,53)$. It is also considered impersonal, which raises concerns about the impact on the clinician-patient relationship, particularly when in-person contact is required for a clinical examination $(36,37)$. In this vein, the "Quebec Emergency Chiefs' Grouping" reported that "Many patients complain of the difficulty of meeting their physician and say they are dissatisfied with the telephone consultation and the dehumanization of care that results" (own translation) (49). It has also been reported that many patients have been "teleconsulted" without their consent. The first instinct of many medical clinics has been to offer consultations by telephone "without even ensuring the patient's consent or assessing whether his/her condition would require a face-to-face consultation" (own translation) (44). In this regard, studies of patient satisfaction, particularly as a measure of quality of care, with telehealth vs. in-person consultations remain scarce (54).

\section{Cost, Remuneration, and Funding Issues}

Whether funding, its scope and nature would be aligned with traditional care and services or whether it would be a separate flow raised as a key issue. In the past, billing for telehealth activities, often higher than for a "traditional" procedure, was mainly done in the context of pilot projects initiated or authorized by the MSSS $(13,14,24)$. The main purpose was to ensure the adherence and participation of physicians in these projects. For COVID-19, and with a view to integrating telehealth into the provision of routine care and services, finances could be a dissuasive factor for the MSSS, especially if there 
is a significant and/or unjustified increase in interventions. Telehealth could also require increased remuneration for other health professionals (e.g., nurses, technologists), those who develop new expertise or perform activities usually reserved for others (e.g., a general practitioner who practices an activity reserved for a cardiologist, a nurse who makes a medical diagnosis).

For Zulman and Verghese (55), "it is a truism in health care that reimbursement shapes practice." One of the reasons for excluding reimbursement for telephone consultations in the 2005-LSSS was the fear of a drift toward "inflation of acts" and the financial impact that this could generate $(4,5)$. Activitybased pricing can lead to perverse behaviors for some clinicians by reducing time (e.g., fewer diagnostic services than in-person visits) and increasing the number of virtual consultations without improving patient outcomes $(47,51)$. Telehealth can also lead to additional downstream consultations, such as compensating for lack of physical examination or reduction of fear of misdiagnosis (51, 56, 57). As previously reported, emergency departments in Quebec have experienced a significant influx of patients referred almost automatically by their physicians after a virtual consultation (double consultation), resulting in additional costs for the HSSS (50).

The FMSQ recognized this risk and questioned physicians early on about potential perverse behaviors and abuses in the billing of telehealth activities in the context of COVID-19. According to the note addressed to its members: "The vast majority [of physicians] apply the letters of agreement [with the MSSS] in an exemplary manner. However, the creativity of some, when it comes to invoicing, harms us all collectively" (own translation). The FMSQ reminds that each billing request must be justified by the medical service rendered and that telehealth activities must be billed in the same way as a regular consultation. However, with telehealth, a single billing may not be suitable for different clinical scenarios. Some complex clinical activities that require a physical examination or monitoring may be difficult to justify in terms of telehealth billing (e.g., biopsy). For its part, the CMQ recognized that there are "signs of abuse" and "there is perhaps too much and more or less appropriate use of this new technology" (own translation) $(44,50)$. Given the lack of established standards of telehealth practice and care, "arbitrary" billing has helped define parameters that have influenced clinicians' practices and behaviors $(55,57)$.

\section{Technology and Infrastructure Issues}

The lack of an integrated and interoperable telehealth platform across Quebec, including a functional electronic health record (EHR), is proving to be a challenge. Direct access by clinicians to telehealth technologies via an integrated EHR is still a "utopia." Telehealth encompasses a variety of services and delivery modalities (e.g., primary care, specialty services, pharmacy, and laboratory) that involve multiple platforms and technological interfaces $(15,58)$. Connecting to different systems several times a day is neither safe nor efficient for the clinician and the patient (2). The time spent moving between multiple systems (e.g., laboratory results, consultation notes) and screens, and dealing with fragmented data, adds an additional layer of effort to an already challenging clinical practice $(38,59)$.

In Quebec, before the pandemic, the use of paper records was still widespread in clinics and hospitals. Part of the communication between physicians, especially for prescriptions, was done by fax $(60,61)$. Some clinicians did not yet have access to the electronic records or did not have the necessary technology in their organizations, such as the ability to document the visit or issue prescriptions $(35,61)$. At the onset of the crisis, the unsystematic use of electronic records was a significant issue when physicians were called upon to provide telehealth services, particularly from their homes. More specifically, there are three different electronic records in Quebec (62), which are not necessarily interoperable: (1) The Quebec Health Record (DSQ): a tool that allows the collection, storage and consultation of citizens' health information, by health care providers. Its objective is to improve the quality of care and the efficiency of the HSSS; (2) Electronic Medical Record (DME): maintained locally by primary care physicians (e.g., private physician's office, family medicine group); (3) The Computerized Clinical Record (DCI): kept by health and social services facilities. Its use and consultation by health care providers are not systematic. The DSQ is not systematically supplied with DCI, in particular because of interfacing problems of the DCI with the information systems of organizations. For example, irregularities in the integrity of prescriptions transmitted electronically by the DSQ, using DME from physicians and software from pharmacists, were revealed in 2019 and required the intervention of the CMQ. Prescriptions retrieved by pharmacists via the DSQ were different from prescriptions printed from the physician's DME (63). One explanation is that DSQ data is not always complete and up-todate (63). The lack of complete information in the patient record and the lack of integration between different technologies and systems may have diminished the value of telehealth in some settings during the crisis. In this vein, a physician may be unable to make a decision when there is a lack of information, or poorquality information, or may make a misdiagnosis or formulate a lower quality diagnosis (e.g., lack of knowledge of patient history and/or current treatments).

Some of the technologies deployed were originally designed and developed for the business world. The lack of flexibility, ergonomics, ease of use, compatibility with existing systems and infrastructures and/or functionalities adapted to local contexts could constitute an obstacle to a quality medical consultation $(16,64)$. Some of the technologies recommended by the Quebec MSSS were incompatible with certain Internet browsers, unusable in environments without high-speed Internet access (e.g., rural and remote areas) and/or did not have downloadable versions for Mac or "old" computers still in use in some health organizations. For example, the Reacts platform was only available on Google Chrome; the Zoom platform had problems with previous versions of Internet Explorer; and the Microsoft Teams platform had problems working on some web browsers (e.g., to support Office 365) and did not allow the patient to access the meeting through a telephone bridge (65-68). Furthermore, interoperability, cybersecurity, and liability issues (e.g., confidentiality, privacy) have made it difficult to integrate 
other technologies, especially those based on remote sensing (e.g., doppler radar, non-contact screening, and monitoring applications), in the care and monitoring of patients, despite the role they could have played in the pandemic (69-71). These issues have made it difficult to effectively use telehealth, especially in creating "digital online care pathways that link rapid and widespread testing with digital symptom checkers, contact tracing, epidemiological intelligence and long-term clinical follow up" (72).

The extraordinary speed with which the technology has been deployed raised concerns about cybersecurity gaps and shortcomings $(22,27,34,35,73)$. The Zoom platform has encountered security issues (e.g., insufficient data encryption) (74). This incident echoes the Wannacry cyberattack that crippled clinical practice and threatened patient safety in Canada and elsewhere (75). In this regard, poor encryption, configuration choices or technology settings could make patient data easily accessible on the Internet (76). Information governance (e.g., generation, storage, transfer, protection, and deletion) and cybersecurity strategies against potential breaches are out of step with the now globalized technological reality $(75,77-79)$.

\section{The Emergence of Private Telehealth Platforms in a Public HSSS}

"Direct-to-consumer" services expanded during the crisis, marketed as solutions to the patient difficulties in accessing overwhelmed public care and services. Indeed, it was difficult to reach the public services "Info-Santé/Info-Social 811" to obtain information and advice that could avoid unnecessary visits to the clinic or the hospital. Private services are not reimbursed by the public health insurance in Quebec (80). They are paid directly by patients ("out-of-pocket"), or through private insurance (e.g., part of employers' services) $(19,80)$.

By their nature, these services are aimed mainly at the youngest, the richest (ability to pay), the most educated (digital literacy) users, living in urban areas, and having a good quality Internet connection (81). In Quebec, consultations via these platforms start at CA $\$ 49$ per consultation (some at CA\$99) (19). These services are as expensive as they are not transparent in their economic and business models (19). It is difficult to find price information before the "consumer" makes an appointment (19). In this regard, the President of Canadian Doctors for Medicare highlights that: "It's a cruel irony that those who could benefit the most from virtual care are least likely to use services that demand upfront payment. In fact, they may even be harmed" (82). Furthermore, even for people who can afford to pay, using these private services means paying twice: once through their public taxes and then through their private employment insurance (83). This is also unfair to those with more resources. In addition, the opacity surrounding the status of certain clinicians employed by these platforms raises concerns about the quality of the services offered and the protection of people in the event of harm $(4,19,84)$. Concerns also arise about conflicts of interest that may appear when the provision of care and services "influences the financial performance of a company" (e.g., unnecessary prescriptions, duplication of care) $(82,85)$. These platforms, when backed by venture capital for example, could further fragment and exacerbate silos as well as inequalities in the HSSS $(19,57,82)$. They also risk diverting human resources away from publicly funded care and services (83).

\section{Digital Divide and Equity Issues}

The pandemic has revealed our society's dependence on digital tools and has highlighted other disparities and inequalities within different categories of the population, which have a significant impact on health (86). It is not entirely surprising that Internet connectivity, the availability of quality and upto-date equipment, and digital literacy are now considered "super-determinants of health": they indeed engage all the other determinants that directly or indirectly influence the health of individuals and communities by now being primarily accessible online (e.g., affordable housing, employment, social assistance, social and family networks, and access to care and services) (86). The crisis has also shown that the technologies used in the delivery of care and services "often neglect those that need them most" as health professionals and technology providers are rarely given the incentive to better meet needs and expectations of underserved populations in terms of digital innovation (86-88).

There is a legitimate concern that telehealth could increase inequalities (e.g., socio-economic, technological, geographic, generational) in access to health care and services (42, 8991). These may include homeless populations, populations with mental health and/or addiction problems, populations with disabilities, the elderly, indigenous populations, immigrant populations, rural and/or isolated communities, etc. (89-91). Under normal circumstances, these populations encounter more accessibility difficulties when requesting an in-person appointment when they need it (28). They already have poor quality health indicators (92). Due to the systematic and systemic difficulties in accessing and using services, the inability to access digital services and interventions can exacerbate these inequalities and difficulties (92). In addition, these populations are more difficult to treat and monitor "virtually" (40). They may simply ignore the existence of these services (82).

The use of the telephone as a means of consultation could mainly concern vulnerable people and fragile socio-economic categories who do not have a high-speed Internet connection, computers and/or smartphones as well as a sufficient digital literacy to use them (33). In certain situations, the telephone could reflect other disparities and inequalities in access to quality care and services for the entire population. In Quebec, only 68\% of people aged 65 and above and only $63 \%$ of adults with an income below $\$ 20,000$ have a computer at home $(89,93,94)$. However, owning a computer does not necessarily imply using it. In rural and remote areas, technological infrastructure and high-speed Internet are lacking $(89,95)$. Some large urban centers could also be affected. For example, in Montreal North, one of the poorest neighborhoods and the most affected by the pandemic in Quebec and Canada, a significant proportion of the residents do not have regular Internet access and/or do not have an e-mail address (e.g., only $30 \%$ of parents in a school board have an email address). For these populations, Internet access is typically available in public spaces, but public libraries have closed during the pandemic $(89,96)$. In this regard, even if public spaces were to 
remain open, these populations may feel uncomfortable accessing information and/or care and services in such an environment (86). According to 2017 data, 340,000 Quebec households did not have access to adequate Internet service (95). In terms of mobile network coverage, some rural and remote areas are still considered "digital deserts" (88). Poor Internet connection is associated with low telehealth use and patient portal use (91).

In addition, smartphones can be expensive for part of the population, which is an additional barrier to equitable access to care and services. In Quebec, the adoption rate of smartphones is 53\% for people with an income below CA $\$ 20,000$ and $35 \%$ for people aged 75 and above $(89,94)$. Similarly, telephone subscriptions in Canada are among the most expensive in the world (e.g., a subscription of CA $\$ 34.31$ in France would cost CA\$64.89 in Germany and CA\$87.32 in Canada) $(97,98)$. Patients who do not have access to Wi-Fi may be forced to use data from their cellular plan, which is a significant cost for some people (67). Indeed, the smartphone could be the main means to Internet access for disadvantaged populations (92). They face barriers such as limited use of data (e.g., "pay-asyou-go" contracts instead of monthly subscriptions) and mobile optimization issues for online content, which affect the use of and engagement of technology for health purposes $(92,99)$. These barriers may be further exacerbated in large low-income families requiring multiple devices and data sharing systems, which would require prioritizing the use of data for specific purposes; in this case, health often comes last (86).

\section{Legal and Regulatory Issues}

Finally, legal and regulatory issues directly or indirectly affect all the aspects mentioned above. The issue of reserved acts and professional skills (e.g., union agreements, recognition of new expertise, enhancement of activity, privileges, and responsibilities) was already recognized as one of the main obstacles to the use of telehealth in Quebec and elsewhere $(13,15,64,100)$. In the context of COVID-19, this has affected other health care providers (e.g., social service staff, occupational therapists, physiotherapists, psychologists) (36). The persistence of certain problems and conflicts related to professional jurisdictions has limited the possibilities of further exploiting their expertise (101).

The emergence of new modes of practice with telehealth, in particular for clinicians working at home in the context of COVID-19, could raise questions of insurance (e.g., workplace, professional risk coverage), practice quality control and compliance with work standards (e.g., ergonomics). For example, the extensive use of technology could have increased the risk of malpractice and lawsuits, especially in cases where the clinician did not have the necessary elements and/or skills to make an informed diagnosis remotely. The lack of information about the conditions under which the technology was used may have forced clinicians to act with caution (29). In fact, during the COVID-19 crisis, the CMQ suspended for 3 months two physicians, who had used teleconsultation, because they "did not make their diagnosis with greatest attention" (own translation) (44).
"Direct-to-consumer" services proliferated in a "legal gray area" and a "policy vacuum" as individuals could pay for medically necessary services that provincial health insurance plans must cover to comply with the basic principles of Canada Health Act (82). Moreover, the management, exchange and processing, or even secondary uses, of the data resulting from these consultations also constituted a gray area in terms of supervision and governance (e.g., commercial use, outsourcing) (15, 64, 78, 82, 84). Recently, Quebec has experienced several high-profile incidents related to the "sale" and/or use for commercial purposes of electronic medical record data without the knowledge of patients (e.g., insurance companies, pharmaceutical industry) $(102,103)$. Due to legal and regulatory gaps, the MSSS recognized that it did not have the power to intervene in certain cases (102).

\section{RECOMMENDATIONS AND AVENUES FOR POLICY AND PRACTICE}

In Quebec, the COVID-19 crisis was a moment of truth for telehealth. Unprecedented deployment and use have been achieved, but many issues were at stake. Despite certain political and organizational initiatives and the publication of notes and guidelines by the MSSS and by professional colleges and federations in previous years, telehealth had not really been considered an essential lever for improving access to care and services. The rapid deployment of telehealth on a large scale during COVID-19 thus represents an "not so quiet" revolution in the delivery of care and services in the Quebec HSSS where, as aptly put by a clinician, "clinical practice will no longer be the same" (own translation) (42).

It is very likely that once the crisis is over, the previous status quo will return as that would be the easy choice. Yet, policy, regulatory and operational changes made in the context of COVID-19 should be maintained and optimized $(1,33)$. This will require strong political and professional leadership, through the management and arbitration of historical oppositions and conflicts between the various stakeholders and levels of governance of the HSSS. In this regard, a digital health strategy should be adopted, which goes beyond a simplistic implementation of technological tools. To operationalize an integrated global and systemic vision of telehealth within the HSSS, certain avenues deserve more attention and action:

- Approaching digital health from a broader public policy perspective: To achieve a true "democracy of health," telehealth should be part of a policy focused on territorial development of rural and remote regions as well as unprivileged urban areas. Such policy should include the deployment of affordable quality technological infrastructure (e.g., universal broadband Internet for all) and basic public services (e.g., free Wi-Fi, subsidized mobile phone plans). Due to their central role in the provision of care and services, digital technologies have been revealed as being part, and mediators, of other determinants of health for individuals and communities $(86,88,91)$. This role has yet to receive the attention it deserves, particularly because telehealth could 
widen the digital divide and worsen health inequalities in society (104). To overcome this "digital exclusion," access to high-speed Internet and technology should now be considered a basic resource as well as a right to health. Hence, "bandwidth as a human right" needs to be more widely discussed (105).

- Ensuring and improving digital literacy: The issue of digital literacy has become prominent during the crisis. This was one of the main obstacles to the use of telehealth (30). Inclusive and equitable digital health requires training and support services that can improve people's digital skills and use of technology (86). Reducing medical jargon by providing resources for interpretation and explanation is key as well as making training and support accessible to everyone, "not just those who are confident enough to request help" (86). Thus, it is necessary to systematically assess the digital skills of any candidate for consultation and/or technology monitoring.

- Ensuring better integration and interoperability of technological systems: Given epidemiological (e.g., chronic diseases) and demographic transitions, and the importance of the determinants of health (e.g., socio-economic, geographic, cultural, environmental), there is a need to ensure better integration and interoperability between the medical, medicosocial and social sectors. For example, investments are required to implement an interoperable "electronic health and social record" capable of integrating other sources of patient data (e.g., individual, social, and systemic determinants of health). The various professionals involved in the trajectory of health care and social services should be able to access and enrich this record (106).

- Establishing a clear framework for governance and organization of telehealth: Telehealth is a marginal practice in the Quebec HSSS. For better integration into routine care and services, a clear telehealth governance (e.g., strategic, tactical, and operational levels) and organizational (e.g., care and service trajectories; protocols, link between primary care and specialized services; links between medical, medico-social, and social services) framework is necessary within the HSSS.

Establishing strong and transparent data governance: The confidence of the population and health care providers in telehealth depends on the way in which the security, confidentiality, and privacy of data are guaranteed (83). Reliable mechanisms for collecting, anonymizing, managing, sharing, storing, securing, and deleting are necessary to ensure efficient, acceptable, proportionate, and equitable use of data for quality and trustworthy care for patients and communities. This trust remains very fragile, especially given the growing role of unconventional actors, mainly from the digital economy (e.g., global tech giants), in the health sector $(83,84)$. To ensure strong and transparent data governance, patients and communities should have a space, protected by a clear legal framework, to express themselves on the services offered, the technologies used, the way and conditions of management and use/re-use of data, and to ensure that their rights are respected (9). Furthermore, technology companies themselves (e.g., software, cloud hosting services, and digital medical devices providers) also need clear data governance and accountability frameworks to operate in a secure, reliable, and standardized digital ecosystem $(83,107)$.

- Reinventing remuneration and funding models: Innovative remuneration and funding models should be developed to promote better inter-professional and organizational collaboration within an operational and integrated telehealth network adapted to patient care and service pathways. Consideration should be given to expanding the scope of practice of certain professional groups (e.g., nurses, pharmacists, and social workers). This funding should promote better integration of telehealth into traditional care and service delivery, not lock it into a separate stream that risks duplicating other silos.

- Modernizing the training of health care providers: Mandatory and credited digital health training programs (initial and continuing) should be in place. Otherwise, integrating telehealth into standard clinical practice will remain elusive even though health care providers are now required to practice in environments where digital technologies have become essential. To date, there is no systematic approach to integrate virtual care in the curricula of most medical schools in Quebec and Canada $(28,108)$. In addition, medical accreditation colleges do not assess the clinical judgment of physicians in the virtual care realm (28).

- Clarifying the place of commercial platforms in a public HSSS: The growing place and role of commercial platforms in the public HSSS should be carefully considered. The government should ensure that these providers contribute in a coherent, complementary, and transparent manner to the mission of the HSSS. There is a risk that certain offers may lead to the emergence and/or exacerbation of inequalities in access to care and services for the population. The HSSS cannot be limited to "fixing market failures," but should be involved in shaping and co-creating innovations with real added value for the population (109).

\section{IMPLICATIONS FOR THE FUTURE AND CONCLUSION}

COVID-19 has stimulated the use of telehealth in the delivery of care and services in an unprecedented way in the HSSS. Great progress has been made, but there have also been challenges and failures. According to Bashshur et al. (1), the problems encountered by telehealth in the context of COVID-19 are acute exacerbations of pre-pandemic systemic problems.

Our observations and findings are in line with what has been reported in the literature on the implementation and use of telehealth. In this regard, experience has shown that integrating telehealth into the delivery of care and services can be complex, especially because of the many changes it could create and the barriers that call into question its added value on the ground $(1,16,33,110)$. Key issues may be human (e.g., patients and clinicians acceptance, and/or indifference), clinical (e.g., quality of care), technical (e.g., interoperability, infrastructure), professional (e.g., changes in practices, 
professional jurisdictions), organizational (e.g., clinicaladministrative processes, organization of care and services), socio-political (e.g., health insurance system, private sector place), economic (e.g., costs, compensation, reimbursements), legal and regulatory (e.g., data governance, patient protection, and professional responsibility), and contextual (e.g., patient profile, local professional dynamics, rural or urban hospitals) $(3,13-16,64,100,111,112)$.

It is too early to fully qualify and quantify the added value of the use of telehealth during the COVID-19 crisis and draw definitive conclusions (72). However, one key finding is that telehealth has become a necessity, not just a convenience (88). The scale of the systemic changes required for its deployment has shown that technology "has outpaced policy" (113). The crisis has highlighted the gap between the obsolete and/or incoherent regulatory, economic, organizational, legal, technological, and clinical-administrative frameworks still in use in the HSSS and the requirements for innovative models of care and service delivery. Thus, it is not possible to envision the future of telehealth without

TABLE 1 | Some challenges and/or collateral effects of telehealth implementation and use.

\begin{tabular}{|c|c|}
\hline Domains & Challenges and/or collateral effects \\
\hline Technological & $\begin{array}{l}\text { - Incompatibility and/or non-interoperability of the technology with existing systems and infrastructures } \\
\text { - Old and/or obsolete technologies and infrastructures } \\
\text { - Need for large storage and archiving capacities } \\
\text { - Low or saturated bandwidth } \\
\text { - New forms of errors: truncation and/or loss of information } \\
\text { - Cybersecurity: confidentiality and data protection } \\
\text { - Difficulty in ensuring the quality and safety control of all software components integrated into the system } \\
\text { - Proprietary technologies: difficulty in developing and/or adapting the technology to the local context }\end{array}$ \\
\hline $\begin{array}{l}\text { Human and } \\
\text { cognitive }\end{array}$ & $\begin{array}{l}\text { - Patient and clinician dependence on technology: screen fatigue, alert fatigue, stress, and anxiety } \\
\text { - Manage and process increasing amounts of information and data: cognitive overload for clinicians and patients } \\
\text { - Rigidity and non-alignment of technology with clinical reality: frustration, exhaustion, and circumvention strategies with risk of error } \\
\text { - "Technology by default": risk of detachment and depersonalization of the patient-clinician relationship } \\
\text { - Literacy ("e-literacy" and "clinical-literacy"): risk of exclusion and/or mismanagement of certain population groups } \\
\text { - Isolation of health professionals: loss of social rituals (e.g., informal relationships, corridor discussions) and contact with colleagues and patients. } \\
\text { Loss of sense of belonging to the organization } \\
\text { - Medicalization of the patient's living space could turn technology into a burden }\end{array}$ \\
\hline Clinical & $\begin{array}{l}\text { - Clinical protocols, good practice guidelines, and ethical standards not adapted or not available } \\
\text { - Inter-organizational telehealth network: problem of clinical interoperability (e.g., harmonization of clinical protocols between different organizations, } \\
\text { variation in clinical practices) } \\
\text { - Large amounts of data: risk of overdiagnosis and overinterpretation } \\
\text { - Clinician's unfamiliarity with technology or poorly adapted technology: suboptimal quality of services and risk of missed diagnosis (e.g., incomplete } \\
\text { or inaccurate examination) } \\
\text { - Low bandwidth and/or obsolete or old technology at the patient's home: suboptimal patient care and/or monitoring } \\
\text { - Non-integrated data and systems: duplication of tasks and increased workload for the clinician }\end{array}$ \\
\hline $\begin{array}{l}\text { Professional } \\
\text { and } \\
\text { Organizational }\end{array}$ & $\begin{array}{l}\text { - Strategic alignment of different stakeholders: what place and what role for telehealth in the planning and organization of services? } \\
\text { - Lack of training and information for clinicians: "resistance to change" } \\
\text { - Emergence of new models of care and service delivery: changes in the organization of services and teamwork } \\
\text { - Overhaul of professional jurisdictions: redefinition of some existing roles and/or emergence of new professional profiles } \\
\text { - Power issues: professional and organizational conflicts by questioning certain balances and hierarchies as well as the redistribution of work, } \\
\text { information, equipment, and resources } \\
\text { - Redistribution of human resources: concentration of expertise in large urban centers despite small rural hospitals } \\
\text { - "One-size-fits-all" approach: weakening of well-functioning local professional and organizational dynamics } \\
\text { - Telehealth in silo: fragmentation of services }\end{array}$ \\
\hline $\begin{array}{l}\text { Legal and } \\
\text { regulatory }\end{array}$ & $\begin{array}{l}\text { - Recognition of telehealth activities as in-person clinical activity: remuneration, quality control, practice standards, and insurance } \\
\text { - Formal recognition of the new roles and responsibilities of certain professional profiles } \\
\text { - Multiplication of stakeholders (e.g., clinicians, patients/consumers, technology providers, organizations, payers, and insurers): dilution of } \\
\text { responsibilities } \\
\text { - Lack of training and information for clinicians on the conditions of use of telehealth: risk of professional misconduct and lawsuits in case of prejudice } \\
\text { - The medico-legal responsibility of clinicians who used the data collected by patients to make a clinical decision } \\
\text { - Data governance: generation, access, use, and exchange; storage, archiving, and deletion; protection against commercial use }\end{array}$ \\
\hline $\begin{array}{l}\text { Economic } \\
\text { and } \\
\text { financial }\end{array}$ & $\begin{array}{l}\text { - Implementation and sustainability: sharing of benefits and costs (e.g., operating costs, human resources, storage, and maintenance) } \\
\text { - Inter-organizational telehealth network: additional costs for some organizations that need to upgrade their technology systems and infrastructures } \\
\text { to align with others; harmonization of the remuneration of clinicians' in different organizations } \\
\text { - New expertise and/or professional profiles: enhancement of remuneration and professional privileges } \\
\text { - Cost of internet subscription and technology (e.g., computer, smartphone) can be prohibitive for some low-income populations } \\
\text { - Over-diagnosis, over-interpretation and sub-optimal patient management: increased costs for the patient and the HSSS } \\
\text { - Fee-for-service billing: perverse behavior and inflation of acts, and additional costs for the patient and the HSSS } \\
\text { - Dependence on certain proprietary technologies: increased costs (fees and additional purchases) for the patient, the organization, and the HSSS }\end{array}$ \\
\hline
\end{tabular}


considering the broader context of the HSSS where it will be deployed (83).

Digital technologies will shape the future of the HSSS, and possibly our societies, by driving the next generation of care and services (87). The form this transformation takes will depend on the choices made in the light of the lessons learned from the pandemic. Industrialized societies face an aging population, chronic diseases, significant socio-demographic and geographic disparities, and possibly future pandemics and health disasters. Digital technologies will have a central role to play in overcoming these challenges. In this regard, decision-makers and all stakeholders will need to think holistically about where "value is most likely to be added, or risks being taken away," when it comes to integrating digital technologies in the delivery of care and services (83). Translating progress into sustainable policies and actions after the pandemic will not be easy, as many key decisions, sometimes with little supporting evidence or controversy, need to be made (114).

As highlighted by Eccleston et al. (115): "Changing practice in such an unplanned way will have positive and negative consequences, many unforeseen." To date, there are few studies on the systemic impacts of this rapid implementation and use of telehealth, but also on the collateral effects of such a change (116). In addition to what was reported in this paper, Table 1 summarizes some of the key issues associated with telehealth implementation and use that have been reported in the literature and need to be considered $(13-16,100,110,117-121)$. It is therefore important to ensure that telehealth can improve access, quality, equity, and efficiency of care and services for the whole population. To do this, its advantages and disadvantages in the context of COVID-19 should be carefully documented in future studies in order to learn from this experience (122). The usefulness of telehealth should also be analyzed beyond the pandemic and its particular circumstances (1). These studies are expected to engage policy-makers, health professionals, patients, communities, and technology providers in the successful and sustainable integration of telehealth into the HSSS.

\section{REFERENCES}

1. Bashshur R, Doarn CR, Frenk JM, Kvedar JC, Woolliscroft JO. Telemedicine and the COVID-19 pandemic, lessons for the future. Telemed eHealth. (2020) 26:571-3. doi: 10.1089/tmj.2020.29040.rb

2. Silven AV, Petrus AH, Villalobos-Quesada M, Dirikgil E, Oerlemans CR, Landstra CP, et al. Telemonitoring for patients with COVID-19: recommendations for design and implementation. J Med Internet Res. (2020) 22:1-10. doi: 10.2196/preprints.20953

3. Garattini L, Martini MB, Mannucci PM. Improving primary care in Europe beyond COVID-19: from telemedicine to organizational reforms. Intern Emerg Med. (2021) 16:255-8. doi: 10.1007/s11739-020-02559-x

4. Alami H, Gagnon M-P, Fortin JP, Kouri R. La télémédecine au Québec: état de la situation des considérations légales, juridiques et déontologiques. Eur Res Telemed. (2015) 4:33-43. doi: 10.1016/j.eurtel.2015. 04.004

5. Ministère de la Santé et des Services sociaux du Québec. La loi Sur Les Services de Santé et les Services Sociaux, LRQ, ch. S-4.2, art. 108.1 et art 108.2. Available online at: http://legisquebec.gouv.qc.ca/fr/ShowDoc/cs/S-4. 2 (aited August 22, 2021).
While this paper is one of the first to provide a systemic analysis of the use of telehealth in the context of COVID19 , it is not without limitations. Without empirical data, it is difficult to draw firm conclusions (9). Furthermore, the article reports findings that are specific to a so-called developed country HSSS. Hence, the recommendations may not be fully relevant to HSSS in so-called developing countries, which may have their own particularities and characteristics. This paper nonetheless offers a rigorous foundation for research, decision-making and practice by systematically examining the conditions that enable and constrain the deployment, use and scale-up of telehealth in the context of COVID-19, but also beyond. To share experiences and stimulate mutual learning, it is also important to conduct research and analysis across countries and jurisdictions. These comparisons can contribute to policy and practical dialogues, which are essential to inform decision-making in a context where societies are increasingly interconnected and interdependent (9).

\section{AUTHOR CONTRIBUTIONS}

HA, PL, RA, J-PF, RF, MN, KO, RR, MA, and BL were engaged in the drafting of the manuscript. All authors read and approved the final manuscript.

\section{FUNDING}

HA was supported by the In Fieri research programme, led by $\mathrm{PL}$, and the International Observatory on the Societal Impacts of Artificial Intelligence and Digital Technologies.

\section{ACKNOWLEDGMENTS}

We thank Dr. Lysanne Rivard (Montreal University) for her insightful comments and feedbacks. We also thank the editor and reviewers for their helpful criticism and suggestions. The ideas presented in the text are those of the authors. They do not necessarily reflect the position of their organizations.

6. Lurie N, Carr BG. The role of telehealth in the medical response to disasters. JAMA Intern Med. (2018) 178:745-6. doi: 10.1001/jamainternmed.2018.1314

7. Latifi R, Tilley EH. Telemedicine for disaster management: can it transform chaos into an organized, structured care from the distance? Am J Disaster Med. (2014) 9:25-37. doi: 10.5055/ajdm.2014.0139

8. Alami H, Rivard L, Lehoux P, Hoffman SJ, Cadeddu SBM, Savoldelli M, et al. Artificial intelligence in health care: laying the Foundation for Responsible, sustainable, and inclusive innovation in low- and middle-income countries. Global Health. (2020) 16:1-6. doi: 10.1186/s12992-020-00584-1

9. Alami H, Lehoux P, Fleet R, Fortin JP, Liu J, Attieh R, et al. How can health systems better prepare for the next pandemic? Lessons learned from the management of COVID-19 in Quebec (Canada). Front Public Health. (2021) 9:671833. doi: 10.3389/fpubh.2021.671833

10. Gouvernement du Canada. Loi Canadienne sur la Santé. Article 7 et suivants (1984). Available online at: https://laws-lois.justice.gc.ca/fra/lois/c6/TexteComplet.html (cited August 22, 2021).

11. Archambault H. Deux fois plus de médecins au privé depuis cinq ans. Le Journal de Montréal. Available online at: https://www.journaldemontreal. com/2018/11/16/deux-fois-plus-de-medecins-au-prive-depuis-cinq-ans (cited August 22, 2021). 
12. Latouche D. La vrai nature de. la Révolution tranquille. Rev Can Sci Polit. (1974) 7:525-36. doi: 10.1017/S0008423900040750

13. Alami H, Fortin JP, Gagnon MP, Pollender H, Têtu B, Tanguay F. The challenges of a complex and innovative telehealth project: a qualitative evaluation of the eastern Quebec Telepathology network. Int J Health Policy Manag. (2018) 7:421-32. doi: 10.15171/ijhpm.2017.106

14. Alami H, Lamothe L, Fortin JP, Gagnon MP. L'implantation de la télésanté et la pérennité de son utilisation au Canada: quelques leçons à retenir. Rec Eur Téléméd. (2016) 5:105-17. doi: 10.1016/j.eurtel.2016.10.001

15. Alami H, Gagnon MP, Fortin JP. Some multidimensional unintended consequences of telehealth utilization: a multi-project evaluation synthesis. Int J Health Policy Manag. (2019) 8:337-52. doi: 10.15171/ijhpm.2019.12

16. Greenhalgh T, Wherton J, Shaw S, Morrison C. Video consultations for covid-19. Br Med J. (2020) 368:1-2. doi: 10.1136/bmj.m998

17. Zhai Y, Wang Y, Zhang M, Gittell JH, Jiang S, Chen B, et al. From isolation to coordination: how can telemedicine help combat the COVID-19 outbreak? medRxiv. (2020) 1-4. doi: 10.1101/2020.02.20.20025957

18. Hollander JE, Carr BG. Virtually perfect? Telemedicine for COVID-19. N Engl J Med. (2020) 382:1679-81. doi: 10.1056/NEJMp2003539

19. Motulsky A, Després P, Petitgand C, Nikiema JN, Régis C, Denis JL. Veille sur les Outils Numériques en Santé Dans le Contexte de COVID-19. Montreal, QC: Observatoire international sur les impacts sociétaux de l'IA et du numérique (OBVIA). (2020) 17 p.

20. Lemay ÉY. Plus de deux millions de rendez-vous en télémédecine. Le Journal de Montréal. Available online at: https://www.journaldemontreal.com/ 2020/07/10/plus-de-deux-millions-de-rendez-vous-en-telemedecine (cited August 22, 2021).

21. Robillard A. Le Québec va changer: les consultations médicales à distance sont là pour rester. Le Journal de Montréal. Available online at: https:// www.journaldemontreal.com/2020/04/11/les-consultations-medicales-adistance-sont-la-pour-rester (cited August 22, 2021).

22. Brunet F, Malas K, Desrosiers ME. Will telemedicine survive after COVID-19? Healthcare Manag Forum. (2021) 34:256-9. doi: 10.1177/08404704211031264

23. Perreault M. Pleins gaz sur la télémédecine. La Presse. Available online at: https://www.lapresse.ca/actualites/sante/2020-03-26/pleins-gazsur-la-telemedecine (cited August 22, 2021).

24. Johnson M. La télémédecine va survivre à la COVID-19 ! Lactualité. Available online at: https://lactualite.com/sante-et-science/la-telemedecineva-survivre-a-la-covid-19/ (cited August 22, 2021).

25. Gris Roy C. Télémédecine: des leçons à tirer de la pandémie. RadioCanada. Available online at: https://ici.radio-canada.ca/nouvelle/1707480/ telemedecine-covid-hausse-demande-maple-communication-medecins (cited August 22, 2021).

26. Collège des Médecins du Québec. La Télémédecine Réalisée par les Résidents et Moniteurs Durant la Pandémie de COVID-19. Collège des Médecins du Québec (2020). 9 p.

27. Collège des Médecins du Québec. Les Téléconsultations Réalisées par les Médecins Durant la Pandémie de COVID-19: Guide à Lintention des Médecins. (2020). 10 p.

28. Glauser W. Virtual care is here to stay, but major challenges remain. Can Med Assoc J. (2020) 192:E868-E9. doi: 10.1503/cmaj.1095884

29. Bhaskar S, Bradley S, Chattu VK, Adisesh A, Nurtazina A, Kyrykbayeva S, et al. Telemedicine as the new outpatient clinic gone digital: position paper from the Pandemic Health System REsilience PROGRAM (REPROGRAM) International Consortium (Part 2). Front Public Health. (2020) 8:410. doi: 10.3389/fpubh.2020.00410

30. Triana AJ, Gusdorf RE, Shah KP, Horst SN. Technology literacy as a barrier to telehealth during COVID-19. Telemed eHealth. (2020) 26:1118-9. doi: 10.1089/tmj.2020.0155

31. Alami H, Gagnon MP, Fortin JP. Involving citizen-patients in the development of telehealth services: qualitative study of experts' and citizenpatients' perspectives. J Particip Med. (2018) 10:1-16. doi.10.2196/10665 doi: 10.2196/10665

32. Alami H, Gagnon MP, Fortin JP. Conditions organisationnelles et systémiques à l'implication des citoyens-patients dans le développement de la télésanté au Québec. Sante Publ. (2019) 31:125-35. doi: $10.3917 /$ spub.191.0125
33. Bashshur RL, Doarn CR, Frenk JM, Kvedar JC, Shannon GW, Woolliscroft JO. Beyond the COVID pandemic, telemedicine, and health care. Telemed eHealth. (2020) 26:1310-3. doi: 10.1089/tmj.2020.0328

34. Accréditation Canada. Trousse COVID-19 Télésanté (2020). Available online at: https://covid19.healthstandards.org/resource/virtual-health-toolkit (cited August 22).

35. Bernier-Sylvestre A, Bourassa E, Caron M. Guide de Soutien Pour la Mise en Euvre des Téléconsultations dans les Établissements de Santé du Québec Dans le Contexte de Pandémie. Québec, QC: Ministère de la santé et des services sociaux du Québec. (2020). 17 p.

36. Fisk M, Livingstone A, Pit SW. Telehealth in the context of COVID19: changing perspectives in Australia, the United Kingdom, and the United States. J Med Internet Res. (2020) 22:1-13. doi: 10.2196/preprints.19264

37. Gilbert AW, Billany JC, Adam R, Martin L, Tobin R, Bagdai S, et al. Rapid implementation of virtual clinics due to COVID-19: report and early evaluation of a quality improvement initiative. BMJ Open Quality. (2020) 9:e000985. doi: 10.1136/bmjoq-2020-000985

38. Alami H, Lehoux P, Gagnon MP, Fortin JP, Fleet R, Ahmed MAA. Rethinking the electronic health record through the quadruple aim: time to align its value with the health system. BMC Med Inf Decis Making. (2020) 20:1-5. doi: 10.1186/s12911-020-1048-9

39. Shanafelt TD, Noseworthy JH, editors. Executive leadership and physician well-being: nine organizational strategies to promote engagement and reduce burnout. Mayo Clinic Proc. (2017) 92:129-46. doi: 10.1016/j.mayocp.2016.10.004

40. Saliba-Gustafsson EA, Miller-Kuhlmann R, Kling SM, Garvert DW, BrownJohnson CG, Lestoquoy AS, et al. Rapid implementation of video visits in neurology during COVID-19: mixed methods evaluation. J Med Internet Res. (2020) 22:1-12. doi: 10.2196/24328

41. Outcome Health. COVID-19 and Australian General Practice: A Preliminary Analysis of Changes Due to Telehealth Use Australia. (2020). 15 p.

42. Beaulieu MD. COVID-19, Télémédecine et Médecine Humaniste: Back to the Future? Réseau-1 Québec. Available online at: https://reseaulquebec.ca/untexte-de-reflexion-de-marie-dominique-beaulieu-covid-19-telemedecineet-medecine-humaniste-back-to- the-future/ (cited August 22, 2021).

43. Reeves JJ, Ayers JW, Longhurst CA. Telehealth in the COVID-19 era: a balancing act to avoid harm. J Med Internet Res. (2021) 23:1-6. doi: $10.2196 / 24785$

44. Méthot D. Téléconsultations: le Collège observe des signes de dérive et de surutilisation. L'Actualité Méd. (2021) 5:1-5.

45. Marin S. Plus de 1,5 million de Québécois ont consulté en télémédecine. La Presse. Available online at: https://www.lapresse.ca/covid-19/2020-0709/plus-de-1-5-million-de-quebecois-ont-consulte-en-telemedecine.php (aited August 22, 2021).

46. Breton M, Catherine H. La première vague de Covid-19 au Québec et les soins primaires. Rev Méd Suisse. (2020) 16:2131-4.

47. Shachar C, Engel J, Elwyn G. Implications for telehealth in a postpandemic future: regulatory and privacy issues. JAMA. (2020) 323:2375-6. doi: 10.1001/jama.2020.7943

48. Park HY, Kwon YM, Jun HR, Jung SE, Kwon SY. Satisfaction survey of patients and medical staff for telephone-based telemedicine during hospital closing due to COVID-19 transmission. Telemed eHealth. (2021) 27:724-32. doi: 10.1089/tmj.2020.0369

49. Lacoursière A. La télémédecine est « un bon outil, mais il a ses limites. $L a$ Presse Available online at: https://www.lapresse.ca/actualites/sante/202104-23/la-telemedecine-est-un-bon-outil-mais-il-a-ses-limites.php (cited August 22, 2021).

50. Boily D, Gentile D. Téléconsultation: le Collège des médecins rappelle à l'ordre les médecins de famille. Radio-Canada. Available online at: https:// ici.radio-canada.ca/nouvelle/1787161/teleconsultation-medecins-famillequebec (cited August 22, 2021).

51. Mehrotra A, Bhatia RS, Snoswell CL. Paying for telemedicine after the pandemic. JAMA. (2021) 325:431-2. doi: 10.1001/jama.2020. 25706

52. Lion KC, Brown JC, Ebel BE, Klein EJ, Strelitz B, Gutman CK, et al. Effect of telephone vs video interpretation on parent comprehension, communication, and utilization in the pediatric emergency department: 
a randomized clinical trial. JAMA Pediatr. (2015) 169:1117-25. doi: 10.1001/jamapediatrics.2015.2630

53. Schulz T, Long K, Kanhutu K, Bayrak I, Johnson D, Fazio T. Telehealth during the coronavirus disease 2019 pandemic: rapid expansion of telehealth outpatient use during a pandemic is possible if the programme is previously established. J Telemed Telecare. (2020) 1-7. doi: 10.1177/1357633X20942045

54. Ramaswamy A, Yu M, Drangsholt S, Ng E, Culligan PJ, Schlegel $\mathrm{PN}$, et al. Patient satisfaction with telemedicine during the COVID-19 pandemic: retrospective cohort study. J Med Internet Res. (2020) 22:1-9. doi: $10.2196 / 20786$

55. Zulman DM, Verghese A. Virtual care, telemedicine visits, and real connection in the era of COVID-19: unforeseen opportunity in the face of adversity. JAMA. (2021) 325:437-8. doi: 10.1001/jama.2020.27304

56. Liu X, Goldenthal S, Li M, Nassiri S, Steppe E, Ellimoottil C. Comparison of telemedicine versus in-person visits on impact of downstream utilization of care. Telemed eHealth. (2021) 1-6. doi: 10.1089/tmj.2020.0286

57. Herzer KR, Pronovost PJ. Ensuring quality in the era of virtual care. JAMA. (2021) 325:429-30. doi: 10.1001/jama.2020.24955

58. Padmanabhan P. With telehealth, one size won't fit all. Healthcare IT News. Available online at: https://www.healthcareitnews.com/blog/telehealth-onesize-wont-fit-all (cited August 22, 2021).

59. Mahal I. Coronavirus has Sped Up Canada's Adoption of Telemedicine. Let's Make That Change Permanent. The Conversation.Available online at: https://theconversation.com/coronavirus-has-sped-up-canadas-adoptionof-telemedicine-lets-make-that-change-permanent-134985 (cited August 22, 2021).

60. Piedboeuf G. Télémédecine: une petite révolution au Québec dans la tempête COVID-19. Radio-Canada. Available online at: https://ici.radio-canada. ca/nouvelle/1679294/telemedecine-quebec-coronavirus-covid-19 (cited August 22, 2021).

61. Collège des Médecins du Québec. Transmission des Ordonnances dans le Contexte de la Pandémie de COVID-19: Mise à Jour. Available online at: http://www.cmq.org/page/fr/covid-19-transmission-des-ordonnancesdans-le-contexte-de-la-pandemie-de-covid-19-mise-a-jour.aspx (cited August 22, 2021).

62. Pierrat A, Maiuri MC, Fleury T. Téléconsultation Synchrone: Analyse des Modèles Existants sur la France, le Danemark, le Canada, les Etats-Unis d'Amérique et Recommandations de Bonnes Pratiques Adaptées au Québec. Montreal, QC (2020). 106 p.

63. Collège des Médecins du Québec. Mise en Garde Concernant le Profil Pharmacologique Provenant $d u$ DSQ. Available online at: http://www. cmq.org/nouvelles-pdf/n-3-2019-03-06-fr-mise-en- garde-concernant-leprofil-pharmacologique-provenant-du-dsq.pdf?t=1607192046595 (cited August 22, 2021).

64. Alami H, Gagnon MP, Côté A, Kostović C, Ahmed MA, Samri M, et al. Au-delà de l'évaluation des bénéfices: réflexion sur les conséquences inattendues de la télésanté. Ethics Med Public Health. (2020) 15:1-7. doi: 10.1016/j.jemep.2020.100596

65. Reacts. Reacts: Questions de Base sur L'application ou Son Utilisation. Available online at: https://reacts.com/fr/faq-covid19-fr/ (cited December 5, 2020).

66. Ministère de la Santé et des Services sociaux du Québec. Zoom: Visioconférence Clinique Pour le Réseau de la Santé - Professionnels de Santé. Foire aux questions: Ministère de la Santé et des Services sociaux du Québec (2020). Available online at: https://telesante.quebec/zoom/professionals-faqfr.html (cited December 5).

67. Réseau québécois de la télésanté. Téléconsultation-Procédure de Convocation d'un Patient via Teams sur Ordinateur. Ministère de la santé et des services sociaux (2020). Available online at: https://telesante.quebec/ guideteams/pdf/Teams_Procedure_Professionnel_Patient_20200515.pdf (cited December 5).

68. Réseau québécois de la télésanté. Rencontre virtuelle Zoom. Ministère de la santé et des services sociaux (2020). Available online at: https://telesante. quebec/zoom/files/Guide_professionnel_Rencontre_virtuelle_Zoom.pdf (cited December 5).

69. Islam S, Fioranelli F, Lubecke V. Can radar remote life sensing technology help combat COVID-19. Front Comms Net. (2021) 2:648181. doi: $10.3389 /$ frcmn.2021.648181
70. Islam S, Kiber M. Optimizing patient-ventilator synchrony utilizing radarbased respiratory features for monitoring COVID-19 patients. Front Comms Net. (2020) 1:636006. doi: 10.3389/frcmn.2020.636006

71. Institut national d'excellence en santé et en services sociaux. COVID-19 et Application Mobile de Télésuivi de Signes Vitaux. Available online at: https:// www.inesss.qc.ca/fileadmin/doc/INESSS/COVID-19/COVID-19_INESSS_ tele_suivi.pdf (cited August 22, 2021).

72. Budd J, Miller BS, Manning EM, Lampos V, Zhuang M, Edelstein M, et al. Digital technologies in the public-health response to COVID-19. Nat Med. (2020) 26:1183-92. doi: 10.1038/s41591-020-1011-4

73. Collège des Médecins du Québec. Télémédecine et Utilisation des Technologies de Linformation et de la Communication. Available online at: http://www.cmq.org/publications-pdf/p-1-2015-02-01-fr-medecintelemedecine-et-tic.pdf (cited August 22, 2021).

74. Joncas $\mathrm{H}$. De la télémédecine avec une application largement critiquée. Le Journal de Montréal. Available online at: https://www.journaldemontreal. com/2020/04/08/de-la-telemedecine-avec-une-application-largementcritiquee (cited August 22, 2021).

75. Alami H, Gagnon MP, Ahmed MAA, Fortin JP. Digital health: cybersecurity is a value creation lever, not only a source of expenditure. Health Policy Technol. (2019) 8:319-21. doi: 10.1016/j.hlpt.2019.09.002

76. Commission Nationale de l'Informatique et des Libertés. Délibération SAN2020-014 du 7 Décembre 2020. Available online at: https://www.legifrance. gouv.fr/cnil/id/CNILTEXT000042675720 (cited August 22, 2021).

77. Iyengar K, Jain V, Vaishya R. Pitfalls in telemedicine consultations in the era of COVID 19 and how to avoid them. Diabetes Metab Syndr. (2020) 14:797-9. doi: 10.1016/j.dsx.2020.06.007

78. Alami H, Gagnon MP, Fortin JP. Telehealth in light of cloud computing: clinical, technological, regulatory and policy issues. J Int Soc Telemed eHealth. (2016) 4:e5.

79. Blandford A, Wesson J, Amalberti R, AlHazme R, Allwihan R. Opportunities and challenges for telehealth within, and beyond, a pandemic. Lancet Global Health. (2020) 8:e1364-e5. doi: 10.1016/S2214-109X(20) 30362-4

80. Perreault M. La télémédecine à la rescousse. La Presse. Available online at: https://www.lapresse.ca/covid-19/2020-03-19/la-telemedecine-ala-rescousse (cited August 22, 2021).

81. Jain T, Mehrotra A. Comparison of direct-to-consumer telemedicine visits with primary care visits. JAMA Netw Open. (2020) 3:1-4. doi: 10.1001/jamanetworkopen.2020.28392

82. Boyle T. Private virtual health services are booming in a 'policy vacuum'. Toronto Star. Available online at: https://www.thestar.com/news/canada/ 2021/01/17/as-pandemic-rages-virtual-health-services-are-booming-in-apolicy-vacuum.html (cited August 22, 2021).

83. Pagliari C. Digital health and primary care: past, pandemic and prospects. $J$ Glob Health. (2021) 11:1-9. doi: 10.7189/jogh.11.01005

84. Alami H, Gagnon MP, Fortin JP. Digital health and the challenge of health systems transformation. Mhealth. (2017) 3:31. doi: $10.21037 /$ mhealth.2017.07.02

85. Glauser W. Virtual care has potential to fragment primary care and disturb continuity of care, warn doctors. CMAJ News. Available online at: http://cmajnews.com/2019/08/29/virtual-care-has-potential-to-fragmentprimary-care-and-disturb-continuity-of-care-warn-doctors/ (cited August 22, 2021).

86. Sieck CJ, Sheon A, Ancker JS, Castek J, Callahan B, Siefer A. Digital inclusion as a social determinant of health. NPJ Digit Med. (2021) 4:1-3. doi: 10.1038/s41746-021-00413-8

87. Van Winkle B, Carpenter N, Moscucci M. Why aren't our digital solutions working for everyone? AMA J Ethics. (2017) 19:1116-24. doi: 10.1001/journalofethics.2017.19.11.stas2-1711

88. Beaunoyer E, Dupéré S, Guitton MJ. COVID-19 and digital inequalities: reciprocal impacts and mitigation strategies. Comput Human Behav. (2020) 111:1-10. doi: 10.1016/j.chb.2020.106424

89. Bahary-Dionne A, Gentelet K. Les Angles Morts des Réponses Technologiques à la Pandémie de COVID-19. Montreal, QC: Observatoire international sur les impacts sociétaux de l'IA et du numérique (OBVIA). (2020). 48 p.

90. Whitelaw S, Mamas MA, Topol E, Van Spall HG. Applications of digital technology in COVID-19 pandemic planning and response. 
Lancet Digit Health. (2020) 2:e435-e40. doi: 10.1016/S2589-7500(20)3 0142-4

91. Velasquez D, Mehrotra A. Ensuring the growth of telehealth during COVID19 does not exacerbate disparities in care. Health Affairs Blog. Available online at: https://www.healthaffairs.org/do/10.1377/hblog20200505.591306/ full/ (cited August 22, 2021).

92. Honeyman M, Maguire D, Evans H, Davies A. Digital Technology and Health Inequalities: A Scoping Review. Cardiff: Public Health Wales NHS Trust. (2020). 44 p. ISBN 978-1-78986-154-121.

93. Guglielminetti B. NETendances : Les Aînés Connectés au Québec. Centre facilitant la recherche et l'innovation dans les organisations. Available online at: https://transformation-numerique.ulaval.ca/wp-content/uploads/2020/ 09/netendances-2019-aines-connectes-au-quebec.pdf/ (cited December 5, 2020).

94. Centre facilitant la recherche et l'innovation dans les organisations. NETendances 2019 - Portrait Numérique des Foyers Québécois. Available online at: https://transformation-numerique.ulaval.ca/wp-content/uploads/ 2020/09/netendances-2019-portrait-numerique-des-foyers-quebecois.pdf (cited December 5, 2020).

95. Poiré M. Internet haute vitesse: vers la fin de la discrimination numérique? Radio-Canada. Available online at: https://ici.radio-canada.ca/nouvelle/ 1070463/internet-haute-vitesse-regions-discrimination-numerique (cited December 5, 2020).

96. Radio-Canada. Coronavirus à Montréal-Nord : un reflet des inégalités sociales: Radio Canada. Available online at: https://ici.radio-canada. ca/premiere/emissions/le-15-18/segments/entrevue/168882/covid-19pandemie-pauvrete (cited December 5, 2020).

97. Schué R. La Vérif: les Canadiens paient-ils trop cher leurs forfaits téléphoniques? Radio-Canada. Available online at: https://ici.radiocanada.ca/nouvelle/1299720/verif-internet-tarifs-facture-canada-australienpd-justin-trudeau-jagmeet-singh (cited December 5, 2020).

98. Gouvernement du Canada. Comparaison des Tarifs des Services Filaires, Sans Fil et Internet Offerts au Canada et à l'étranger - Édition de. (2018). Available online at: https://www.ic.gc.ca/eic/site/693.nsf/fra/00169.html\#a00 (cited December 5, 2020).

99. Graetz I, Huang J, Brand R, Hsu J, Yamin CK, Reed ME. Bridging the digital divide: mobile access to personal health records among patients with diabetes. Am J Manag Care. (2018) 24:43-8.

100. Alami H, Fortin JP, Gagnon MP, Lamothe L, Ahmed MAA, Roy D. Cadre stratégique pour soutenir l'évaluation des projets complexes et innovants en santé numérique. Sante Publ. (2020) 32:221-8. doi: 10.3917/spub.202.0221

101. Dubois CA. COVID-19 et Main-D'œuvre en Santé: Des Politiques de Rupture Pour Briser le Cycle de Reproduction des Fragilités Actuelles. Montreal, QC: CIRANO. (2020). 7 p.

102. Malboeuf MC. Dossiers médicaux à vendre. La Presse. Available online at: https://www.lapresse.ca/actualites/sante/201803/02/01-5155859-dossiersmedicaux-a-vendre.php (cited December 5, 2020).

103. Yvan-Lemay É, Lachance N. La "vente" des données de santé est déjà amorcée. Le Journal de Montréal. Available online at: https://www. journaldemontreal.com/2020/08/28/la-vente-des-donnees-de-sante-estdeja-amorcee (cited December 5, 2020).

104. Valdez RS, Rogers CC, Claypool H, Trieshmann L, Frye O, WellbelovedStone C, et al. Ensuring full participation of people with disabilities in an era of telehealth. JAMIA. (2020) 28:389-92. doi: 10.1093/jamia/ocaa297

105. Tang A, Lehoux P. Le Numérique Dans Tous Ses États: Une Responsabilité Partagée Entre la Société Civile, le Secteur Public et le Secteur Privé. Monteal, QC: École de santé publique de l'Université de Montréal (2021).

106. Granier V. Loi d'accélération et de simplification de l'action publique: les mesures concernant le numérique en santé. TIC-Santé. Available online at: https://www.ticsante.com/story/5479/loi-d-acceleration-etde-simplification-de-1-action-publique-les-mesures-concernant-lenumerique-en-sante.html (cited August 22, 2021).

107. Wolff J, Pauling J, Keck A, Baumbach J. Success Factors of Artificial Intelligence Implementation in Healthcare. Front Digit Health. (2021) 3:594971. doi: 10.3389/fdgth.2021.594971

108. Echelard J-F, Méthot F, Nguyen H-A, Pomey M-P. Medical student training in eHealth: scoping review. JMIR Med Educ. (2020) 6:1-16. doi: $10.2196 /$ preprints. 20027
109. Mazzucato M, Roy V. Rethinking value in health innovation: from mystifications towards prescriptions. J Econ Policy Reform. (2019) 22:101-19. doi: $10.1080 / 17487870.2018 .1509712$

110. Greenhalgh T, Koh GCH, Car J. Covid-19: a remote assessment in primary care. BMJ. (2020) 368:m1182. doi: 10.1136/bmj.m1182

111. Alami H, Gagnon M-P, Wootton R, Fortin J-P, Zanaboni P. Exploring factors associated with the uneven utilization of telemedicine in Norway: a mixed methods study. BMC Med Inf Decis Making. (2017) 17:180. doi: 10.1186/s12911-017-0576-4

112. Kim AY, Choi WS. Considerations on the implementation of the telemedicine system encountered with stakeholders' resistance in COVID19 pandemic. Telemed eHealth. (2020) 27:475-80. doi: 10.1089/tmj.2020. 0293

113. Rheuban K, Shanahan C, Willson K. Telemedicine: innovation has outpaced policy. AMA J Ethics. (2014) 16:1002-9. doi: 10.1001/virtualmentor.2014.16.12.pfor1-1412

114. Loris U-P, Martineau M. Telehealth After COVID-19: Clarifying Policy Goals for a Way Forward. Santa Monica, CA: RAND Corporation. (2021). 5 p.

115. Eccleston C, Blyth FM, Dear BF, Fisher EA, Keefe FJ, Lynch ME, et al. Managing patients with chronic pain during the COVID19 outbreak: considerations for the rapid introduction of remotely supported (eHealth) pain management services. Pain. (2020) 161:889-93. doi: $10.1097 /$ j.pain.0000000000001885

116. Murphy M, Scott LJ, Salisbury C, Turner A, Scott A, Denholm R, et al. Implementation of remote consulting in UK primary care following the COVID-19 pandemic: a mixed-methods longitudinal study. Br J Gen Pract. (2021) 71:e166-e77. doi: 10.3399/BJGP.2020. 0948

117. Rubió FS, Sellens JT, Ramos IS, Sáez CA, Kotzeva A, Hidalgo JV. Framework for the Implementation of a Telemedicine Service. Washington, DC: Pan American Health Organization (2016). 76 p.

118. Greenhalgh T, Russell J. Why do evaluations of eHealth programs fail? An alternative set of guiding principles. PLoS Med. (2010) 7:e1000360. doi: 10.1371/journal.pmed.1000360

119. Greenhalgh T, Wherton J, Papoutsi C, Lynch J, Hughes G, A'Court C, et al. Beyond adoption: a new framework for theorizing and evaluating nonadoption, abandonment, and challenges to the scale-up, spread, and sustainability of health and care technologies. J Med Internet Res. (2017) 19:1-21. doi: 10.2196/jmir.8775

120. Joseph V, West RM, Shickle D, Keen J, Clamp S. Key challenges in the development and implementation of telehealth projects. J Telemed Telecare. (2011) 17:71-7. doi: 10.1258/jtt.2010.100315

121. Zhang T, Mosier J, Subbian V. Identifying barriers to and opportunities for telehealth implementation amidst the COVID-19 pandemic by using a human factors approach: a leap into the future of health care delivery? JMIR Hum Factors. (2021) 8:1-9. doi: 10.2196/24860

122. Latifi R, Doarn CR. Perspective on COVID-19: finally, telemedicine at center stage. Telemed eHealth. (2020) 26:1106-9. doi: 10.1089/tmj.2020. 0132

Conflict of Interest: The authors declare that the research was conducted in the absence of any commercial or financial relationships that could be construed as a potential conflict of interest.

Publisher's Note: All claims expressed in this article are solely those of the authors and do not necessarily represent those of their affiliated organizations, or those of the publisher, the editors and the reviewers. Any product that may be evaluated in this article, or claim that may be made by its manufacturer, is not guaranteed or endorsed by the publisher.

Copyright (๑) 2021 Alami, Lehoux, Attieh, Fortin, Fleet, Niang, Offredo, Rouquet, $\mathrm{Ag}$ Ahmed and Ly. This is an open-access article distributed under the terms of the Creative Commons Attribution License (CC BY). The use, distribution or reproduction in other forums is permitted, provided the original author(s) and the copyright owner(s) are credited and that the original publication in this journal is cited, in accordance with accepted academic practice. No use, distribution or reproduction is permitted which does not comply with these terms. 